IRA-International Journal of Applied Sciences ISSN 2455-4499; Vol.04, Issue 01 (2016)

Institute of Research Advances

http://research-advances.org/index.php/IRAJAS

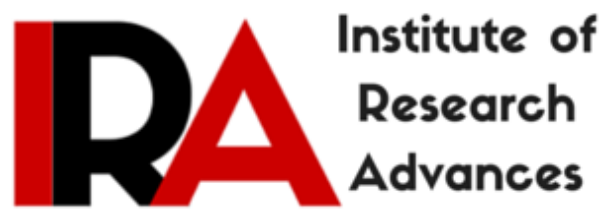

\title{
L - Fuzzy BP - Algebras
}

Christopher Jefferson Y. ${ }^{1}$ \& M. Chandramouleeswaran ${ }^{2}$

${ }^{1}$ Dept. of Mathematics, Spicer Adventist University

Pune - 411 007, Maharashtra, India.

${ }^{2}$ Head, PG \& Research Dept. of Mathematics, S.B.K. College

Aruppukottai - 626 101, Tamilnadu, India.

DOI: http://dx.doi.org/10.21013/jas.v4.n1.p8

\section{How to cite this paper:}

Jefferson Y., C., \& Chandramouleeswaran, M. (2016). L - Fuzzy BP - Algebras. IRAInternational Journal of Applied Sciences (ISSN 2455-4499), 4(1).

doi:http://dx.doi.org/10.21013/jas.v4.n1.p8

(C) Institute of Research Advances

(cc) EY-NC

This works is licensed under a Creative Commons Attribution-Non Commercial 4.0 International License subject to proper citation to the publication source of the work.

Disclaimer: The scholarly papers as reviewed and published by the Institute of Research Advances (IRA) are the views and opinions of their respective authors and are not the views or opinions of the IRA. The IRA disclaims of any harm or loss caused due to the published content to any party. 


ABSTRACT
In this paper, we define the notion of L-Fuzzy BP-Algebras. We discuss the properties of L-Fuzzy BP-
subalgebras and prove results on the notion of Intersection of L-fuzzy BP-subalgebras and Cartesian
product of L-fuzzy BP-subalgebras.

Key words: BP-algebra, Fuzzy BP-algebra, L-Fuzzy BP-algebra

1. Introduction: In 1966 Y.Imai and K.Iseki introduced two classes of abstract algebra, BCK algebras and BCI algebras [3,4]. In 2012 Sun Shin Ahn and Jeong Soon Han introduced the notion of BP-Algebras [6]. In 1971 A.Rosenfeld initiated the study of fuzzy algebraic structures [5] In 1965 L.A.Zadeh introduced the notion of fuzzy sets [7]. L Goguen extended the notion of fuzzy sets into L-fuzzy sets where L is a complete lattice [2]. In our earlier paper we have introduced the notion of fuzzy structures in BP-algebras [1]. In this paper, we introduce the notion of L-Fuzzy BP-Algebras.

\section{Preliminaries}

In this section we recall some basic definitions that are needed for our work.

Definition 2.1 A BP- algebra $(\mathrm{X}, *, 0)$ is a non-empty set $\mathrm{X}$ with a constant 0 and a binary operation $*$ satisfying the following conditions:

$$
\begin{array}{ll}
\text { 1. } & \mathrm{x} * \mathrm{x}=0 \\
\text { 2. } & \mathrm{x} *(\mathrm{x} * \mathrm{y})=\mathrm{y} \\
\text { 3. } & (\mathrm{x} * \mathrm{z}) *(\mathrm{y} * \mathrm{z})=\mathrm{x} * \mathrm{y}), \text { for any } \mathrm{x}, \mathrm{y}, \mathrm{z} \in \mathrm{X}
\end{array}
$$

Definition 2.2 Let $S$ be a non-empty set. A mapping $\mu: S \rightarrow[0,1]$ is called a fuzzy subset of $S$.

Definition 2.3 A lattice is a partially ordered set in which any two elements have a least upper bound and a greatest lower bound.

Definition 2.4 A lattice $\mathrm{L}$ is called a complete lattice if every subset $\mathrm{A}=\left\{a_{\alpha}\right\}$ has a sup denoted by $\mathrm{V} a_{\alpha}$ and inf denoted by $\wedge a_{\alpha}$ where $0 \equiv \wedge a_{\alpha}$ is the least element of $\mathrm{L}$ and $1 \equiv \wedge a_{\alpha}$ is the greatest element of L: $0 \leq \mathrm{a}$ and $1 \geq$ a for every $\mathrm{a} \in \mathrm{L}$.

Definition 2.5 Let $X$ be a non-empty set and $\mathrm{L}:(\mathrm{L}, \leq)$ be a complete lattice with least element 0 and greatest element 1 . A L-fuzzy subset $\mu$ of $X$ is a function $\mu: X \rightarrow L$.

\section{L-Fuzzy BP-subalgebra}

In this section we introduce the notion of L-Fuzzy BP-subalgebra. Throughout this section L denote complete Lattice.

Definition 3.1 :A L- fuzzy subset $\mu$ of a BP-algebra $(X, *, 0)$ is called a L-fuzzy BP subalgebra of $X$ if, for all $\mathrm{x}, \mathrm{y} \in \mathrm{X}$ the following condition is satisfied

$$
\mu(\mathrm{x} * \mathrm{y}) \geq \mu(\mathrm{x}) \wedge \mu(\mathrm{y})
$$


Example 3.2Let $X=\{0, a, b, c\}$ be a set with the following table

Then $(\mathrm{X}, *, 0)$ is a $\mathrm{BP}-$ algebra

\begin{tabular}{|l|l|l|l|l|}
\hline$*$ & 0 & $\mathrm{a}$ & $\mathrm{b}$ & $\mathrm{c}$ \\
\hline 0 & 0 & $\mathrm{a}$ & $\mathrm{b}$ & $\mathrm{c}$ \\
\hline $\mathrm{a}$ & $\mathrm{a}$ & 0 & $\mathrm{c}$ & $\mathrm{b}$ \\
\hline $\mathrm{b}$ & $\mathrm{b}$ & $\mathrm{c}$ & 0 & $\mathrm{a}$ \\
\hline $\mathrm{c}$ & $\mathrm{c}$ & $\mathrm{b}$ & $\mathrm{a}$ & 0 \\
\hline
\end{tabular}

Define $\mu: X \rightarrow$ L by $\mu(x)=\left\{\begin{array}{l}1 \text { if } x=0 \\ t_{1} \text { if } x=b \\ t_{2} \text { if } x=a \\ 0 \text { if } x=c\end{array}\right.$

$\mathrm{t}_{1}, \mathrm{t}_{2} \in \mathrm{L}$ and $\inf \mathrm{L} \leq \mathrm{t}_{1} \leq \mathrm{t}_{2} \leq \operatorname{Sup} \mathrm{L}$

Then $\mu$ is a L-fuzzy BP-subalgebra of $\mathrm{X}$.

One can easily prove that:

Theorem 3.4 Intersection of any two L-fuzzy BP-sub algebras of X is again a L fuzzy BP-sub algebra.

Definition 3.5 Let $\mu$ be any L-fuzzy subset of a BP-algebra $(X, *, 0)$ and let $t \in L$

The set $U(\mu, t)=\{x \in X: \mu(x) \geq t\}$

is called a level subset of $\mu$ of $X$.

Lemma 3.6 Let $(X, *, 0)$ be a BP-sub algebra. Let $\mu$ be a L-fuzzy BP-subalgebra of $X$.

Let $\alpha \in L$. Then

1. $U(\mu, \alpha)$ is either $\emptyset$ or a $B P$ - sub algebra of $X$

2. $\mu(0) \geq \mu(\mathrm{x})$ for all $x \in \boldsymbol{X}$

\section{Proof:}

For any $\alpha \in \mathrm{L}$, assume that $\mathrm{U}(\mu, \alpha)$ is non-empty .

Let $\mathrm{x}, \mathrm{y} \in \mathrm{U}(\mu, \alpha)$. Therefore $\mu(x) \geq \alpha, \mu(y) \geq \alpha$

To show that $\mathrm{U}(\mu, \alpha)$ is a BP - subalgebra, we need to show $\mathrm{x} * \mathrm{y} \in \mathrm{U}(\mu, \alpha)$.

That is, we need to show

$$
\begin{aligned}
\mu(x * y) & \geq \mu(\mathrm{x}) \wedge \mu(\mathrm{y}) \\
& \geq \alpha \wedge \alpha \\
& =\alpha
\end{aligned}
$$

Also, $\mu(0)=\mu(x * x) \geq \mu(x) \wedge \mu(x)=\mu(x)$

Since $\mathrm{x} * \mathrm{x}=0 \forall \mathrm{x} \in \mathrm{X}$

Thus $\mu(0) \geq \mu(x), \forall x \in X$

Lemma 3.7 A L-fuzzy subset $\mu$ of a BP-subalgebra $X$ is a L fuzzy BP-subalgebra if and only if for all $t \in L$, the level set of $\mu, U(\mu, t)$ is either empty or a BP-subalgebra of $X$.

Proof:

Assume that the level subset of $\mu$ in $X$,

$\mathrm{U}(\mu, \mathrm{t}) \neq \varnothing$

Then for any $x, y \in U(\mu, t)$,

$$
\mu(\mathrm{x}) \geq \mathrm{t}, \mu(\mathrm{y}) \geq \mathrm{t}
$$


Now, $\quad \mu(\mathrm{x} * \mathrm{y}) \geq \mu(\mathrm{x}) \wedge \mu(\mathrm{y}) \geq \mathrm{t}$

which implies $\mathrm{X} * \mathrm{y} \in \mathrm{U}(\mu, \mathrm{t})$ and hence $\mathrm{U}(\mu, \mathrm{t})$ is a $\mathrm{BP}$ - subalgebra of $\mathrm{X}$.

Conversely assume that $\mathrm{U}(\mu, \mathrm{t})$ is a BP-subalgebra of $\mathrm{X}$

Take $\mathrm{t}=\mu(\mathrm{x}) \wedge \mu(\mathrm{y})$ for any $\mathrm{x}, y \in \mathrm{X}$

$\mathrm{x}, y \in \mathrm{X}$ implies $\mathrm{x} * \mathrm{y} \in \mathrm{U}(\mu, \mathrm{t})$

Hence $\mu(\mathrm{x} * \mathrm{y}) \geq \mathrm{t}=\mu(\mathrm{x}) \wedge \mu(\mathrm{y})$, thus proving that $\mu$ is a L-fuzzy BP - subalgebra of $\mathrm{X}$.

As in the case of Fuzzy BP algebra one can prove the following Lemma3.8 and Theorem 3.9.

Lemma 3.8 Any BP-subalgebra of a BP-algebra $\left(X,{ }^{*}, 0\right)$ can be realized as a level subalgebra of some $L$ fuzzy BP-subalgebra of $X$

Theorem 3.9 Let $A$ be a subset of $X$. Then the characteristic function $\chi_{A}$ is a L-fuzzy BP-subalgebra of $X$ if and only if $A$ is a $B P$ - subalgebra of $X$

Theorem 3.10 Let $\mu$ be a L-fuzzy BP- subalgebra of $(X, *, 0)$ with finite image. If $U(\mu, s)=U(\mu, t)$ for some $s, t \in \operatorname{Im}(\mu)$, then $s=t$.

\section{Proof:}

Let $\mu$ be a L-fuzzy BP-subalgebra of $X$ with finite image such that

$\mathrm{U}(\mu, \mathrm{s})=\mathrm{U}(\mu, \mathrm{t})$ for some $\mathrm{s}, \mathrm{t} \in \operatorname{Im}(\mu)$.

Now, $\mu$ is a L-fuzzy algebra of $X$ shows that $U(\mu, s)$ is a BP-subalgebra.

Therefore, if $\mathrm{x}, \mathrm{y} \in \mathrm{U}(\mu, \mathrm{t})=\mathrm{U}(\mu, \mathrm{s})$ then $\mu(\mathrm{x}) \geq \mathrm{t}$ and $\mu(\mathrm{y}) \geq \mathrm{t}$.

Also, $x, y \in U(\mu, t)=U(\mu, s)$ and $U(\mu, s)$ is a BP-subalgebra shows that $x * y \in U(\mu, s)$.

This shows that

$\mu(\mathrm{x} * \mathrm{y}) \geq \mu(\mathrm{x}) \wedge \mu(\mathrm{y}) \geq \mathrm{s}$.

Thus we have, $\mu(x * y) \geq \mathrm{s}$ as well as $\mu(\mathrm{x} * \mathrm{y}) \geq \mathrm{t}$ whenever $\mathrm{x}, \mathrm{y} \in \mathrm{U}(\mu, \mathrm{t})=\mathrm{U}(\mu, \mathrm{s})$.

Similarly, we can prove that, $\mu(\mathrm{x} * \mathrm{y}) \geq \mathrm{s}$ as well as $\mu(\mathrm{x} * \mathrm{y}) \geq \mathrm{t}$ whenever $\mathrm{x}, \mathrm{y} \in \mathrm{U}(\mu, \mathrm{s})=\mathrm{U}(\mu, \mathrm{t})$.

This proves that $\mathrm{s}=\mathrm{t}$.

Lemma 3.11 Let $\mu$ and $\lambda$ be two $L$ - fuzzy $B P-$ sub algebras of $X$ with identical family of level $B P-s u b$ algebras. If $\operatorname{Im}(\mu)=\left\{t_{1}, t_{2}, \ldots . t_{n}\right\}$ and $\operatorname{Im}(\lambda)=\left\{s_{1}, s_{2}, \ldots \ldots, s_{m}\right\}$ where $F$

$t_{1} \geq t_{2} \geq \ldots . \geq t_{n}$ and $s_{1} \geq s_{2} \geq, \ldots . . \geq s_{m}$ Then

$$
\begin{array}{ll}
\text { 1. } & m=n \\
\text { 2. } & U\left(\mu, t_{i}\right)=U\left(\lambda, s_{i}\right) \text { for } i=1,2, \ldots . n \\
\text { 3. } & \text { If } \mu(x)=s_{i}, \text { then } \lambda(x)=s_{i}, \forall x \in X \text { and } i=1,2, \ldots \ldots n
\end{array}
$$

\section{Proof:}

Let $\mu$ and $\lambda$ be two L-fuzzy BP - sub algebras of X with identical family of level BP - sub algebras $F(\mu)$

$=F(\lambda)$.

Let $\operatorname{Im}(\mu)=\left\{t_{1}, t_{2}, \ldots . t_{n}\right\}$ where $t_{1} \geq t_{2} \geq \ldots . t_{n}$

and $\operatorname{Im}(\lambda)=\left\{s_{1}, s_{2}, \ldots ., s_{m}\right\}$ where $s_{1} \geq s_{2} \geq, \ldots \ldots, \geq s_{m}$

(1.1) implies $U\left(\mu, t_{1}\right) \subseteq U\left(\mu, t_{2}\right) \subseteq \ldots . \subseteq U\left(\mu, t_{n}\right)=X$

(1.2) implies $U\left(\lambda, s_{1}\right) \subseteq U\left(\lambda, s_{2}\right) \subseteq \ldots . \subseteq U\left(\lambda, s_{n}\right)=X$

and $F(\mu)=\left\{U\left(\mu, t_{i}\right): 1 \leq i \leq n\right\}$,

$F(\lambda)=\left\{U\left(\lambda, s_{i}\right): 1 \leq j \leq m\right\}$

Assume $m \neq n$.

Then, $\mathrm{m} \geq \mathrm{n}$ or $\mathrm{n} \geq \mathrm{m}$.

Let $\mathrm{m} \geq \mathrm{n}$.

Then $U\left(\mu, t_{i}\right)=U\left(\lambda, s_{i}\right), i=1,2, \ldots \ldots n$.

This shows that both $t_{i}$ and $s_{i} \in \operatorname{Im}(\mu)$.

For $\mathrm{i}>\mathrm{n}$ we observe that $\mathrm{t}_{\mathrm{i}} \notin \operatorname{Im}(\mu)$ and hence, 
$U\left(\mu, t_{i}\right) \neq U\left(\lambda, s_{i}\right) i=n+1, n+2, \ldots m$.

Let $\mathrm{n} \geq \mathrm{m}$. Then $U\left(\mu, t_{i}\right)=U\left(\lambda, s_{i,}\right)$

$i=1,2, \ldots \ldots m$. This shows that both $t_{i}$ and $\operatorname{si} \in \operatorname{Im}(\lambda)$. For $\mathrm{j}>\mathrm{m}$ we observe that $\mathrm{s}_{\mathrm{j}} \notin \operatorname{Im}(\mu)$ and hence,

$U\left(\mu, t_{i}\right) \neq U\left(\lambda, s_{i}\right) i=m+1, m+2, \ldots n$.

(1.3) and (1.4) implies $t_{i} \neq$, $s_{i,}$

$\forall i=1,2, \ldots \ldots n$

Hence we can find some i such that $U\left(\mu, t_{i}\right) \neq U\left(\lambda, s_{i}\right)$.

This contradicts that $F(\mu)=F(\lambda)$.

Hence we conclude that $\mathrm{m}=\mathrm{n}$.

1. By part(1), we have proved that $m=n$. Since $\mu$ and $\lambda$ have identical family of level sub algebras, we have

$$
U\left(\mu, t_{i}\right)=U\left(\lambda, s_{i}\right), \quad i=1,2, \ldots \ldots n .
$$

2. Follows from (1) and (2)

Let $\mu(\mathrm{x})=t_{i}$, implies $\lambda(\mathrm{x})=s_{i}$, for $i=1,2, \ldots, n$

Theorem 3.12Let $\mu$ and $\lambda$ be two $L$ - fuzzy sub algebras of $X$ with identical family of level sub algebras.

Then $\operatorname{Im}(\mu)=\operatorname{Im}(\lambda)$ implies $\mu=\lambda$

Proof:

Let $\mu$ and $\lambda$ be two L-fuzzy sub algebras of $X$ with identical family of level sub algebras.

Let $\operatorname{Im}(\mu)=\operatorname{Im}(\lambda)=\left\{s_{1}, s_{2}, \ldots ., s_{n}\right\}$

Where $s_{1} \geq s_{2} \geq, \ldots ., \geq s_{n}$

By lemma 3.11 for any $\mathrm{x} \in \mathrm{X}$, there exists $\mathrm{s}_{\mathrm{i}}$ such that $\mu(x)=s_{i}=\lambda(\mathrm{x})$.

Thus $\mu(x)=\lambda(\mathrm{x}) \forall x \in X$, proving that $\mu=\lambda$

Theorem 3.13 Two level BP-sub algebras $U(\mu, s)$ and $U(\mu, t),(s<t)$ of a $L$ fuzzy $B P$ - subalgebra $\mu$ are equal if and only if there is no $x \in X$ such that $s \leq \mu(x)<\mathrm{t}$.

Proof:

Let $U(\mu, s)$ and $U(\mu, t)$ be two level BP-sub algebras of L-fuzzy BP-subalgebra $\mu$ of $X$

Suppose that $\mathrm{U}(\mu, \mathrm{s})=\mathrm{U}(\mu, \mathrm{t})$ for some $s<t$.

Suppose there is one $\mathrm{x} \in \mathrm{X}$ such that $s \leq \mu(x)<\mathrm{t}$.

Then, $\mu(x) \geq \mathrm{s}$ and $\mu(x)<\mathrm{t}$.

That is, $\mathrm{x} \in \mathrm{U}(\mu, \mathrm{s})$ and $\mathrm{x} \notin \mathrm{U}(\mu, \mathrm{t})$.

This contradicts the fact that $\mathrm{U}(\mu, \mathrm{s})=\mathrm{U}(\mu, \mathrm{t})$.

Conversely, assume that there is no $\mathrm{x} \in \mathrm{X}$ such that $s \leq \mu(x)<\mathrm{t}$.

Suppose, $\mathrm{U}(\mu, \mathrm{s}) \neq \mathrm{U}(\mu, \mathrm{t})$

For, $\mathrm{x} \in \mathrm{U}(\mu, \mathrm{t}) \Rightarrow \mu(x) \geq \mathrm{t}>\mathrm{s}$

$$
\Rightarrow \mu(x)>\mathrm{s} \Longrightarrow \mathrm{x} \in \mathrm{U}(\mu, \mathrm{s})
$$

Since

$\mathrm{U}(\mu, \mathrm{s}) \neq \mathrm{U}(\mu, \mathrm{t})$, choose $\mathrm{U}(\mu, \mathrm{s}) \nsubseteq \mathrm{U}(\mu, \mathrm{t})$.

Hence there is an $\mathrm{x} \in \mathrm{U}(\mu, \mathrm{s})$ and

$\mathrm{x} \notin \mathrm{U}(\mu, \mathrm{t}) . \quad \Rightarrow \mu(\mathrm{x}) \geq \mathrm{s}$ and $\mu(\mathrm{x})<\mathrm{t}$.

Thus there exists an element $\mathrm{x} \in \mathrm{X}$ such that $s \leq \mu(x)<\mathrm{t}$, this contradicts our hypothesis.

Hence $U(\mu, s)=U(\mu, t)$.

Definition 3.14 Let $\lambda$ and $\mu$ be the L-fuzzy set in a set $X$. The Cartesian product $\lambda \mathrm{x} \mu: \mathrm{X} \times \mathrm{X} \rightarrow[0,1]$ is defined by $(\lambda \mathrm{x} \mu)(\mathrm{x}, \mathrm{y})=\{\lambda(\mathrm{x}) \wedge \mu(\mathrm{y})\} \forall \mathrm{x} \in \mathrm{X}$. 
Theorem 3.15 If $\mu_{1}$ and $\mu_{2}$ are L-fuzzy $B P-$ sub algebras of $X$, then $\mu=\mu_{1} \times \mu_{2}$ is a L-fuzzy $B P-$ subalgebra of $X \times X$.

Proof:

For any $\left(\mathrm{x}_{1}, \mathrm{x}_{2}\right)$ and $\left(\mathrm{y}_{1}, \mathrm{y}_{2}\right) \in \mathrm{X} \mathrm{x}$, we have,

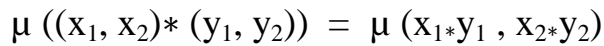

$$
\begin{aligned}
& =\left(\mu_{1} \times \mu_{2}\right)\left(\mathrm{x}_{1 *} \mathrm{y}_{1}, \mathrm{x}_{2 *} \mathrm{y}_{2}\right) \\
& =\mu_{1}\left(\mathrm{x}_{1 * \mathrm{y}_{1}}\right) \wedge \mu_{2}\left(\mathrm{x}_{2 *} \mathrm{y}_{2}\right) \\
& \geq\left(\mu_{1}\left(\mathrm{x}_{1}\right) \wedge \mu_{1}\left(\mathrm{y}_{1}\right)\right) \wedge\left(\mu_{2}\left(\mathrm{x}_{2}\right) \wedge \mu_{2}\left(\mathrm{y}_{2}\right)\right) \\
& =\left(\mu_{1}\left(\mathrm{x}_{1}\right) \wedge\left(\mu_{2}\left(\mathrm{x}_{2}\right)\right) \wedge\left(\mu_{1}\left(\mathrm{y}_{1}\right) \wedge \mu_{2}\left(\mathrm{y}_{2}\right)\right)\right. \\
& =\left(\mu_{1} \mathrm{x} \mu_{2}\right)\left(\mathrm{x}_{1}, \mathrm{x}_{2}\right) \wedge\left(\mu_{1} \mathrm{x} \mu_{2}\right)\left(\mathrm{y}_{1}, \mathrm{y}_{2}\right) \\
& =\mu\left(\mathrm{x}_{1}, \mathrm{x}_{2}\right) \wedge \mu\left(\mathrm{y}_{1}, \mathrm{y}_{2}\right)
\end{aligned}
$$

Hence $\mu=\mu_{1} \times \mu_{2}$ is a L-fuzzy BP - subalgebra of $\mathrm{X} \times \mathrm{X}$.

Definition 3.16 Let $\left(X_{1}, *_{1}, O_{1}\right)$ and $\left(X_{2}, *_{2}, O_{2}\right)$ be BP-algebras. A mapping $f: X_{1} \rightarrow X_{2}$ is called a homorphism if,

$$
f\left(x *{ }_{1} y\right)=f(x) *_{2} f(y) \forall x, y \in X
$$

Definition 3.17 Let $f$ be any function from the BP-algebra $X_{1}$ to the $B P$-algebra $X_{2}$. Let $\mu$ be any fuzzy $\mathrm{BP}$ - subalgebra of $\mathrm{X}_{1}$ satisfying supremum property and $\sigma$ be any fuzzy $\mathrm{BP}$ - subalgebra of $\mathrm{X}_{2}$. The image of $\mu$ under $f$, denoted by $f(\mu)$, is $L$ - fuzzy subset of $X_{2}$ defined by

$\left(\mathrm{f}(\mu(\mathrm{y}))=\left\{\begin{array}{lc}\operatorname{Sup}_{x \in f^{-1}(Y)} \mu(x) & \text { if } f^{-1}(y) \neq \varnothing \\ 0 & \text { otherwise }\end{array}\right.\right.$

where $y \in \mathrm{X}_{2}$. The pre image of $\sigma$ under $\mathrm{f}$, symbolized by $f^{-1}(\sigma)$, is a L-fuzzy subset of $\mathrm{X}_{1}$ defined by $\left(f^{-1}(\sigma)\right)(\mathrm{x})=\sigma(\mathrm{f}(\mathrm{x})) \forall x, \in X_{1}$.

Lemma 3.18 $\operatorname{Let}\left(X_{1},{ }_{1}, O_{1}\right)$ and $\left(X_{2},{ }_{2}, O_{2}\right)$ be two BP-algebras. Let $f: X_{1} \rightarrow X_{2}$ be an epimorphism. If $\sigma$ is L fuzzy BP-subalgebra of $X_{2}$, then $f^{-1}(\sigma)$ is a L-fuzzy BP-subalgebra of $X_{1}$.

Alternatively, we have epimorphic pre image of a $L$-fuzzy BP-subalgebra is a L-fuzzy BP-sub algebra.

Proof:

$$
\begin{aligned}
\left(f^{-1}(\sigma)\right)\left(\mathrm{x} *{ }_{1} \mathrm{y}\right) & =\sigma\left(\mathrm{f}\left(\mathrm{x} *{ }_{1} \mathrm{y}\right)\right) \\
& =\sigma\left(\mathrm{f}(\mathrm{x}) *{ }_{2} \mathrm{f}(\mathrm{y})\right) \text { since } \mathrm{f} \text { is an epimorphism } \\
& \geq(\sigma(\mathrm{f}(\mathrm{x}) \wedge \sigma(\mathrm{f}(\mathrm{y}))) \text { since } \sigma \text { is a L-fuzzy } \mathrm{BP}-\text { sub algebra } \\
& \left.\left.\left.=\left(f^{-1}(\sigma)\right)(\mathrm{x}) \wedge f^{-1}(\sigma)\right)(\mathrm{x})\right)\right) \forall x, y \in X
\end{aligned}
$$

Thus $f^{-1}(\sigma)$ is a L-fuzzy BP-subalgebra of $\mathrm{X}_{1}$.

Lemma 3.19 An epimorphic image of a $L$ - fuzzy BP-subalgebra satisfying sup property is a L-fuzzy BPsub algebra. That is, let $f: X_{1} \rightarrow X_{2}$ be an epimorphism of BP-algebras. If $\mu$ is a L-fuzzy BP subalgebra of $X_{1}$ with sup property, then $f(\mu)$ is a L fuzzy BP - subalgebra of $X_{2}$.

Proof:

Let $f(x), f(y) \in f\left(X_{1}\right)$ and let $x_{0} \in f^{-1}(f(x))$, and $y_{0} \in f^{-1}(f(y))$, be such that

$$
\begin{aligned}
\mu\left(x_{0}\right) & =\operatorname{Sup}_{a \in \mathrm{f}^{-1}(f(x))} \mu(\mathrm{a}) \\
\mu\left(y_{0}\right) & =\operatorname{Sup}_{b \in \mathrm{f}^{-1}(f(y))} \mu(\mathrm{b})\left(f(\mu)\left(\mathrm{x}^{*} \mathrm{y}\right)\right. \\
& =\operatorname{Sup}_{a \in \mathrm{f}^{-1}(f(x * y))} \mu(\mathrm{a}) \text { if }^{-1}(\mathrm{x} * \mathrm{y}) \neq \varnothing .
\end{aligned}
$$

Let $\mathrm{A}=f^{-1}(f(x)), \quad B=f^{-1}(f(y)), \quad C=f^{-1}(f(x) . f(y))$

$\mathrm{A} * \mathrm{~B}=\left\{x \in X_{1}: x=a * b: a \in A, b \in B\right\}, x \in A * B$

$f(x)=f(a * b)=f(a) * f(b), x \in\left(f^{-1} f(a) * f(b)\right)$ implies $A * B \subseteq C$. 
Now,

$$
\begin{aligned}
f(\mu)\left(f(a) *_{2} f(b)\right) & =\operatorname{Sup}_{\left.a \in \mathrm{f}^{-1}\left(f(a) *_{2} f(b)\right)\right)} \mu(\mathrm{x}) \\
& =\operatorname{Sup}_{x \in \mathrm{C}} \mu(\mathrm{x}) \geq \operatorname{Sup}_{x \in \mathrm{A} * \mathrm{~B}} \mu(\mathrm{x}) \geq \operatorname{Sup}_{a \in \mathrm{A}, \mathrm{b} \in \mathrm{B}} \mu\left(a *_{1} b\right) \\
& \geq \operatorname{Sup}_{a \in \mathrm{A}, \mathrm{b} \in \mathrm{B}}(\mu(\mathrm{a}) \wedge \mu(\mathrm{b})) \\
& =\operatorname{Sup}_{a \in \mathrm{A}, \mathrm{b} \in \mathrm{B}}(\mu(\mathrm{a}) \wedge \mu(\mathrm{b})) \\
& =\operatorname{Sup}_{a \in \mathrm{f}^{-1}(f(x))} \mu(\mathrm{a}) \wedge \operatorname{Sup}_{b \in \mathrm{f}^{-1}(f(x))} \mu(\mathrm{b}) \\
& =f(\mu(\mathrm{a})) \wedge f(\mu(\mathrm{a}))
\end{aligned}
$$

Thus an epimorphic image of a L-fuzzy BP - subalgebra satisfying the sup property is a L-fuzzy $B P$ - subalgebra.

\section{References}

[1] Christopher Jefferson Y., M. Chandramouleeswaran, Fuzzy Algebraic Structure in BPAlgebras, Mathematical Sciences International Research Journal Vol.4(2) (2015), 336-340

[2] Goguen J.A., L-Fuzzy Sets, Journal of Mathematical Analysis and Application 18 (1967), $145-174$

[3] Imai, Y.; Iseki, K. On axiom systems of propositional calculi, XIV.Proceedings of the Japan Academy, v. 42, n. 1, p. 19-22, 1966.

[4] Iseki, K, On BCI-algebras, Math. Seminar Notes 8 (1980), 125-130

[5] Rosenfeld, A. Fuzzy groups. Journal of Mathematical Analysis and Applications, v. 35, n. 3, p. 512$517,1971$.

[6] Sun Shin Ahn \& Jeong Soon Han, On BP-Algebras, Hacettepe Journal Of Mathematics and Statistics 42(5) (2013), $551-557$.

[7] Zadeh, L. A. Fuzzy sets. Information and Control, v. 8, n. 3 (1965), p. 338-353 